\title{
EFFECTS OF 1988 FIRES ON ECOLOGY OF COYOTES IN Yellowstone National Park: BASEline Preceding Possible Wolf Recovery
}

\author{
ROBERT L. CRABTREE • BIOLOGY DEPARTMENT \\ MONTANA STATE UNIVERSITY $\bullet$ BOZEMEN
}

\section{- ABSTRACT}

Fifty-four healthy coyotes (Canis latrans) and 32, 8-12 week old pups captured at dens were radiotagged in the Lamar Valley and Blacktail Plateau areas of the northern range of Yellowstone National Park. Seven of the 40 captured in the fall were 6 month-old pups which suggest slow population productivity. Adults range in age from 1 to 12 years and averaged nearly 4 years old. Territorial packs in both study areas are adjacent, non-overlapping, contiguous, and averaged $15 \mathrm{~km}^{2} /$ We estimate that 85 to $90 \%$ of coyotes on the northern range belong to packs. A territorial group or pack during the winter consists of 2 alpha individuals, 2 or 3 beta adults, and 2 or 3 adult-sized pups (average pack size $=7$ ). Nine adults were killed (2 mountain lion [Felis concolar], 2 road-kill, 2 shot, and 3 unknown) which equates to a $15 \%$ annual mortality rate. Eleven of 36 pups have died between the ages of 3 and 9 months old. Population productivity ranges from 2.0 to 2.7 pups recruited per territory. The reproductive failure rate among breeding groups averaged $15 \%$ during 1990 and 1991. Initial coyote density estimates are 0.09 per $\mathrm{km}^{2}$. Intensive foraging observations were conducted from January through June 1991. In 353 hours of focal observations 427 capture attempts were made on small mammal prey with $162(38 \%)$ successful. Habitat type played a key role in the success rate. Mesic meadows had the highest capture rates followed by willow/meadow habitats and sage habitat. Small mammals, especially voles (Microtus
\end{abstract}

spp.), dominate the diet with ungulate remains becoming important in May through July, presumably elk (Cervus elaphus) calves and late winter, mostly scavenging. We have observed numerous successful and unsuccessful predation attempts on ungulates in our study areas. Coyotes appear to impact ungulate numbers in 3 ways: predation on calves and fawns shortly after birth (up to 8 weeks), predation on short-yearlings and adults during winter, and indirect impact from harassment of other predators at ungulate-kills. Coyotes may be the major ungulate predator on the northern range due to cooperative social and foraging behavior, their ability to take advantage of vulnerable ungulates, and their high population levels. Wolf (Canis lupus) extirpation has probably resulted in high coyote population densities.

\section{$\checkmark \quad$ INTRODUCTION}

The ecology of natural, unexploited coyote populations is, for the most part, unknown. Whether research is management-oriented or of evolutionary significance, the ecology of natural coyote populations must be understood in the absence of human exploitation. Yellowstone National Park should provide the ideal situation for such an investigation. Not since Adolph Murie's landmark study 50 years ago (Murie 1940) has an comprehensive, objective study of coyote ecology been undertaken in the Yellowstone ecosystem. 
The objectives of this project are to:

1. Assess effects of 1988 fires on coyote survival, reproduction, activities, pack and terrritorial dynamics.

2. Estimate coyote population density and quantify their ecological role preceding potential wolf restoration.

3. Quantify the effect of winter elk carrion availability and mule deer (Odocoileus hemionus) density on coyote population dynamics.

4. Describe coyote seasonal responses to movements of elk and mule deer.

5. Test if coyote pack size is related to prey size, territory size, size of litters, and pup survival.

6. Describe interspecific interactions among scavengers.

7. Document predation on ranch livestock by coyotes from Yellowstone, and on allotments on National Forests adjacent to the northern range.

8. Develop and test a social-class structured population model in comparison to sex- and age-structured approaches.

9. Estimate parameters for, and develop an empirically-based energetic model that explains the variation in spatial location, movement, and reproductive success of coyotes based on various underlying themes (prey base, habitat, slope, aspect, etc.).

\section{$\checkmark \quad$ METHODS}

\section{GENERAL POPULATION DEMOGRAPHY AND SOCIAL ECOLOGY}

Adult coyotes will be captured with padded, offset leghold traps (Soft-catch, Woodstream, Inc.) with attached tranquilizer tabs (Balser 1965). Other injury-minimizing (and avoidance of non-target species) modifications were developed by Crabtree (1989) who incurred no major injuries and no deaths in 121 captures of 112 individual coyotes. We will also capture coyotes with a remote-triggered, fencenet near carcasses during winter.

The sex, weight, estimated age, condition indices (Crabtree 1989), presence of scars and unique marks, and description of genitalia and mammae will be determined for each coyote. The vestigial first premolar will be extracted from an anaesthetized lower jaw for age analysis via cementum annuli examination. Each coyote will be ear-marked and fitted with a modified (Crabtree 1989) 3-year radio collar weighing $3 \%$ of body weight. Blood samples will be taken for serological analysis and SNA fingerprinting.

All baseline ecological data will be collected according to 3 biological seasons: whelping, 15 April to 15 July; pup-rearing, 15 July through 15 October; and winter (breeding), 15 October through 15 April. At the end of each biological season, pre-defined transects will be canvassed to collect coyote feces. This will allow correlation of biological-season specific movements, habitat use, and behavior with foraging ecology and food habits.

Coyotes will be radio-tracked with a variety of techniques including a fixed-station null-peak system. Resident coyotes will be located every hour during 12 night sessions each biological season. Coyotes will be located only during active periods determined by remote activity-monitors and infrequent 24-hour sessions. Non-resident coyotes will be monitored approximately two times per week. Individual residency times (Crabtree 1989) on the pre-selected core study area will be estimated to aid in the determination of social class, population social composition, and population density (Dennis et al. 1991). Coyotes will be assigned social status based on the classification criteria of Crabtree (1989) who studied a natural, unexploited population.

The above methods will allow for the estimation of emigration (dispersal), immigration, survival, mortality factors, territorial turnover, social class transition probabilities, and population productivity. Maximum-likelihood estimates of survival and mortality factors will be generated with the program SURVIV (White 1984) and modified with the KaplanMeier staggered-entry models (Pollock 1989). This analysis will allow survival and mortality factors to be estimated and statistically tested by year, age 
class, social class, season, and sex. Litter size will be determined from den counts and occasional (if any) female carcasses. The proportion of females in the population that breed will be estimated from activity and movement data during whelping as verified by Crabtree (1989). A modified Markov transition/Leslie matrix model based on social-class specific mortality and fecundity will be constructed (Crabtree, unpublished manuscript) to estimate population growth rate and social-class transition probabilities.

Pups will be hand captured at dens when 9-12 weeks old and surgically implanted with intraperitoneal radio-transmitters. This will allow estimates of early pup mortality, dispersal, and social interaction and transitions up to 2 years of age.

Coyote home ranges and utilization distributions (probability density functions) will be estimated with an adaptive kernel method (Worton 1989) using a recently developed computer program (Garton and Crabtree 1989, unpublished). For comparative purposes the minimum convex polygon (Mohr 1947) and harmonic mean (Dixon and Chapman 1980) methods will be calculated. Seasonal spatial overlap indices will be calculated based on volume overlap of animals' utilization distributions (program OVERLAP [Leban and Crabtree 1988]).

\section{SPECIFIC METHODS FOR FIELD-ORIENTED OBJECTIVES 1 THROUGH 7}

1. We will quantify the following coyote responses: survival, reproduction, changes in social status, territoriality, group size, food habits, prey consumption, seasonal home range shifts, and foraging activity and location. We will treat the territory or coyote social group as the sampling unit and conduct a "gradient analysis" (Ter Braak and Prentice 1988) in the form of a linear model. Extensive effort will be placed in capturing at least one (or both) alpha adult(s) in at least 12 territories located across a gradient of fire intensities and burn types (e.g., forest, shrubland, and sedge) with 4 of 12 territories located in unburned, "control" areas. We simply seek to explain the variation among territorial group response variables (dependent variables above) by measurement of habitat variables such as cover, burn characteristics, and prey abundances of each territory (independent variables).

2. We will utilize a modified mark-recapture method known as radioisotope feces-tagging that has much promise and has recently been implemented to directly estimate coyote population size and density (Dennis et al. 1991). Captured coyotes are administered a tag that marks the feces. This averts recapture biases, eliminates the need for recapture of coyotes, and provides large sample sizes and more precise estimates.

We propose 2 unique and innovative approaches to determine the ecological role of the coyote with emphasis on their impact on prey species. First, we will utilize a differential digestability model recently developed and apply it to our population of coyotes. Secondly, we will estimate predation rates on prey species based on the highly observable and habituated coyote population of Yellowstone's northern range.

We will not only examine food habits from scat analysis but apply a method that estimates the actual fresh weight of prey ingested for each prey species (elk, mule deer, antelope [Antilocarpan americana], microtines, etc.). This differential digestability model was recently completed (Kelly 1991). This model corrects the bias due to differential digestion of prey items. This research was the result of an extensive, highly controlled and replicated series of feeding trials involving 50 coyotes, 37 prey species combinations, and multiple examination of over 1,600 coyote scats. Differential digestability of different prey types caused a severe bias which means current methods are highly inaccurate. Even the gross ranking of preferred food items based on percent frequency of occurrence of prey items in scats can be highly misleading. Differential digestibility was found to be a complex function of physiological parameters such as feeding time strategies, retention time and passage rates in the stomach, and surface area to volume ratios of prey types.

Besides the application of the differentialdigestability model, the key to estimating the actual biomass of prey consumed by a population of coyotes (e.g., Lamar Valley) is estimating the population size of coyotes (this we have) and estimating coyote defecation rates. There are 3 ways we propose to 
obtain estimates of defecation rates. First, the above pen study will provide an estimate, but a degree of uncertainty exists as to whether this is representative of the real field situation. A second estimate can be obtained from dividing the total number of observed defecations by the total number of observed coyoteshours. A third estimate can be obtained from snowtracking coyotes and recording the distance in between defecations. Because the routes of snowtracked coyotes can be determined from radiotracking, the distances between defecations can be converted into time-specific rates. Other events revealed from snow-tracking, like urination scentmarking and predation attempts, can similarly be converted to time-specific rates.

Because we can collect a sample of scats from the interior core area of a territory with certainty that those scats are from that pack we can again, determine the effect of fire, available prey, group size, etc. on prey type consumed. Crabtree et al. (1989) individually marked and identified the scats from 44 coyotes and verified that over $95 \%$ of the scats collected from inside the home-range core area are from the resident pack themselves.

3. We will estimate both the availability of elk carrion (and other ungulate carrion) and mule deer density and relate this to coyote population dynamics at 2 levels: the individual territory and the total coyote population (over time). Concurrent with the winter transects addressed in objective \#6, we will conduct winter ground transects on the northern winter range in order to estimate the availability of carrion. Estimates of mule deer density will be gathered from other ongoing research efforts in the park.

Thus, as in objective \#1, an individual territory's survival, reproduction, change in social status, territoriality, group size, food habits, prey consumption, seasonal home range shifts, and foraging activity and location will be relaated to, and tested for the availability estimates of carrion and mule deer (gradient analysis). Additional estimates of other ungulate prey (e.g., antelope fawns) may also be addressed in the same manner as mule deer availability.

4. We will examine the following coyote response to ungulate movements both to and from the winter range at both the territory and population level: diet shifts, changes in activity patterns, territorial behavior and carcass interactions (objective \#6), home range shifts, and pack size. The radiotelemetry and winter observational data will be analyzed temporally with divisions centered on spring and fall ungulate migrations, coyote breeding and pair bonding, and alpha female parturition and weaning periods. Finally, paired comparison of responses will made between territorial and non-territorial individuals.

5. Group or pack size will be determined by a combination of methods: visual sightings from ground and aerial observation during December through March when group cohesiveness is maximized, ratio estimate from marked feces (Crabtree et al. 1989), and most importantly, vocalization monitoring and carcass observations.

6. Besides the nocturnal and crepuscular radiotracking periods during the winter period, we will conduct a supplemental study. We will observe coyote interactions at carcasses utilizing modified focal sampling procedures (Altmann 1974) and record behavioral information into a cassette tape and video recorder. Behavioral interactions such as dominance display, fighting, and usurping within and between coyote packs will be recorded in relation to these various factors: territorial area (core area, periphery, and boundary), group size, carrion availability, season, sex, food deprivation/satiation, and age of territorial establishment. Supplementation of carcasses to improve a balanced design and create carcass interactions at observational vantage points will be conducted.

Concurrent with carcass transects (objective \#3) we will record all predator tracks (coyote, red fox (Vulpes vulpes), bobcat (Felis rufus), marten (Martes americana), cougar, wolverine (Gulo gulo), etc.). Besides snow-track surveys, sightings and scats will be monitored to provide a baseline index to abundance before possible wolf presence. 
7. There exists no valid method to ascertain actual coyote depredations unless the carcass is fresh. However, we propose to make contact by letter, telephone, and personal visitation to local private ranches with livestock on private and National Forest land. Estimated dispersal rate and dispersal direction from Yellowstone coyotes will be compared on a seasonal and yearly basis to the response by livestock owners and other involved personnel (e.g., Montana Dept. of Fish and Game).

\section{$\checkmark \quad$ RESULTS AND DISCUSSION}

Field work began in fall 1989 in the Lamar Valley and Blacktail Plateau areas of northern Yellowstone. Since then we have maintained our goal of 1 to 3 marked adults in all social groups in both study areas. Lamar Valley has 7 social groups or "packs", whereas Blacktail Plateau has 5. Including only the areas adjacent to, and either side of the paved highway there are 20 social groups from the west end of Blacktail Plateau to the east end of Lamar Valley.

Fifty-four adult coyotes have been captured ( 24 $\mathrm{F}, 20 \mathrm{M}$ ) in Lamar and Blacktail areas during fall/winter and spring trapping periods. Seventeen coyotes were trapped and radio-collared this fall (13 adults and 4 pups). Six of these were instrumented with activity collars. Trap success was high and still averaged approximately 40 trap nights/coyote. In addition, 9 badgers (Taxidea taxus), 2 red fox, 1 striped skunk (Mephitis mephitis), and 1 raccoon (Procyon lotor) were captured during these capture periods.

Seven of 40 coyotes (18\%) captured in the fall were 6 month-old pups which may indicate low population productivity. The age of adults $(11+$ months and older) ranged from 1 to 12 years and averaged 3.6 years. To our knowledge this is the oldest average age yet reported in any coyote study.

Nineteen pups were hand-captured at dens in June 1991. Pups were isolated from den entrances and "grabbed" or were forced out of their dens with a wire-ferret device. Eighteen of these were surgically implanted with a intraperitoneal transmitter
(45 g) and released. One pup was not implanted because of its low weight and poor condition.

\section{SOCIAL AND SPATIAL ORGANIZATION}

Territorial packs in both study areas are adjacent, non-overlapping, contiguous, and averaged $15 \mathrm{~km}^{2}$. We estimate that 85 to $90 \%$ of coyotes on the northern range belong to packs. As in other studies of coyote social ecology, a northern range pack or territorial group consists of a dominant, mated alpha-pair and subordinate "beta" individuals. These betas are pups from previous litters that remain in the natal area.

We calculate that during the winter, an average northern range pack consists of 2 alpha individuals, 2 or 3 beta adults, and 2 or 3 adult-sized pups (average pack size $=7$ ). Approximately one beta adult in each pack has a loose affiliation with its natal area and has a movement area much larger than the territory size. We have noted an anomaly whereby a beta female from the Amythest pack had joined the neighboring Bison Peak pack during the pup-rearing season.

We are currently analyzing data from a pilot study of coyote behavior at carcasses conducted from January to April 1991. Preliminary results suggest that pack access to a carcass is a function of initial discovery, its location with respect to territorial boundaries, and level of hunger. Within a pack, the alpha male has first feeding access and is occasionally tolerant of the alpha female but not subordinate betas and pups. Carcass observations will continue this winter with increased effort and sample sizes.

\section{POPULATION DEMOGRAPHICS}

Based on visual capture-recapture and territory enumeration, the population density of coyotes on the northern range appears to be very high. Preliminary estimates averaged 0.09 adult coyotes per $\mathbf{k m}^{2}$. We are currently finishing the counting of scats for presence of the isotope-label. Twenty-two percent of the first 500 scats counted were labeled. This ratio of marked to unmarked scats will allow an independent estimate of population density.

Annual adult mortality rate is $15 \%$. Nine deaths have occurred of which 2 were due to vehicles, 2 were shot off the study area after 
dispersing, and 5 natural mortalities. Of 5 natural mortalities, 2 were killed by mountain lions, and 3 were unknown causes (suspect mountain lion killed M990).

Four of 13 pups radio-tagged in 1990 died of natural causes; one 2 months after capture and 3 in early winter (one killed by a mountain lion). This resulted in an overall pup mortality of $55 \%$ in 1990. So far, 7 of 22 pups radio-tagged in 1991 have died of natural causes. In four of the mortalities, pups were approximately half their normal weights at that age. This mortality combined with the disappearance of $33 \%$ of the pups from May through June results in a 55\% mortality rate as of November 1991. Reproductive failure rate among territorial packs was $17 \%$ in 1990 and $13 \%$ in 1991 . These data result in an overall estimate of population productivity between 2.0 and 2.7 pups recruited per pack.

Surprisingly, no pup dispersal occurred in 1990 and only 3 of 22 pups captured in 1991 have dispersed as of 1 November. The remaining pups become betas in their natal packs. However, at least 4 of 17 betas adults have dispersed in the late summer/early fall period.

\section{FORAGING ECOLOGY}

Seventeen coyotes $(10 \mathrm{~m}, 7 \mathrm{f})$ were observed from 15 January to 15 April 1991. A total of 223 hours of observation were collected on foraging and social behavior (including mating and scent-marking behavior). We observed 264 capture attempts with $92(35 \%)$ successful. Habitat type played a key role in the success rate. Mesic meadows and willow/meadow habitats had the highest capture rate at $36 \%$ and $44 \%$, respectively. Sage habitat had the lowest success rate at $28 \%$. These different success likely reflected different prey densities and prey vulnerabilities.

Thirteen coyotes ( $10 \mathrm{~m}, 3 \mathrm{f})$ were observed from 16 April to 15 July 1991 . A total of 130 hours of observation were collected on foraging and social behavior including adult-pup interactions and territorial defense. We observed 163 capture attempts with 70 (43\%) successful. Mesic meadows and willow/meadow habitat, again, had the highest success rate at $47 \%$ and $40 \%$, respectively, whereas sage habitat was low at $33 \%$.
Observations of foraging and social behavior began again in November 1991 and will continue through July 1992. Further analysis of foraging rates will include the influenece of snow depth and type, habitat, sex, social class, and age.

The $273 \mathrm{~km}$ scat-survey transects conducted at the end of each biological season resulted in the collection of 300 to 400 samples. We have subsampled 160 scats from each collection period and have begun analysis of food habits and estimates of prey biomass consumed. Preliminary results indicate that small mammals, especially voles, dominate the diet with ungulate remains becoming important in May through July (presumably elk calves) and late winter (mostley scavenging).

We have observed numerous successful and unsuccessful predation attempts on ungulates in our study areas. Coyotes appear to impact ungulate numbers in 3 ways: predation on calves and fawns shortly after birth (up to 8 weeks), predation on short-yearlings and adults during winter, and indirect impact from harassment of other predators at ungulate-kills. Although coyote predation on ungulates has not been directly looked at, the following informtion strongly suggests that coyote predation on ungulates is a significant factor and that the coyote is currently the major ungulate predator on the northern range. Of course this could dramatically change with the recolonization of wolves.

A recent elk calf mortality study (B. Harting, unpubl. data, 1991) indicated a $7,7,10$, and $35 \%$ annual coyote predation rate in Lamar Valley during $1987,1988,1989$, and 1990, respectively. This corresponds to the remains of 1 to 3 elk calves per coyote den found during June at both study areas in 1990 and 1991. Based on searches of denning sites (coyotes generally move 4 or 5 times the first 10 weeks after birth) we calculate a minimum of 8 calves killed (and brought back to the den) per territorial pack. We also have found intact elk calves killed by coyotes and not utilized.

Based on preliminary analysis of a small sample of marked antelope fawns, it appears that coyote predation was $80 \%$ on northern range pronghorn fawns in 1991 (D. Scott, pers. commun., 1991). We also suspect high coyote predation rates on mule deer fawns. 
Coyote predation on elk during the winter months appears to be a function of increased vulnerability, snow conditions and slope (G. Green, pers. commun., 1988) and the size and condition of short-yearlings. Besides noting several successful and unsuccessful predation attempts on short-yearling elk (and one successful attempt on an adult mule deer), we noted a healthy 2 or 3 year old cow that was attacked and killed by a pack of coyotes in Lamar Valley in February 1990. During carcass surveys conducted on the northern range in 1987 (Knight et al. 1988) researchers were able to verify that coyotes killed 3 of 5 short-yearling elk for carcasses discovered 0 to 4 days after death; and 2 of 7 short-yearlings discovered 4 to 16 days after death. An additional 28 short-yearlings were found 16 to 90 days after death but cause of mortality could not be attributed to a predator.

Another means by which coyotes numerically impact ungulate populations is through harassment of other ungulate predators thereby forcing them to abandon their kill and kill unguates at a higher rate. During intensive observations in recent years, coyotes have been observed usurping both mountain lions and grizzly bears (Ursus arctos) from their kills. Without coyote harassment, lions apparently spend 2 to 3 times longer feeding at a kill (G. Felzien, unpubl. data, 1991). In one instance, a coyote pack was observed usurping, attacking, and biting a grizzly bear (S. French, pers. commun., 1991).

Although it is difficult to quantify the direct impact of coyotes on ungulate populations, it is feasible that coyotes could be removing 1000 or more elk annually. The average elk calf mortality reported was above $15 \%$. Crudely extrapolated to the northern range, fifteen percent of, say, 6000 elk calves is 900 elk removed by elk calf predation alone. Compared to an estimated 350 to 400 elk removed by mountain lions annually (K. Murphy, pers. commun. 1991), coyotes may present an important influence on ungulate populations (especially on low populations of antelope and mule deer). This impact is function of coyote population size which may be at unnaturally high levels due to the extirpation of wolves. Based on extrapolations from our study areas to other similar areas on the northern range with known coyote presence, we estimate at least 450 coyotes (60 packs) on the northern range.

\section{$\checkmark \quad$ CONCLUSIONS}

The northern Yellowstone population has characteristics similar to the natural, unexploited population in south-central Washington studied by Crabtree (1989): low productivity, a highly-structured social system, a contiguous distribution of nonoverlapping, year-round territories, and an old-age structure. Adult mortality is low and primarily due to mountian lions. Like wolves (Canis lupus), 85 to 90\% of the northern Yellowstone coyote population exists in packs and average pack size is high. Northern range coyotes prey primarily on small mammal prey, but ungulate prey is an important food source seasonally. Coyotes may be the major ungulate predator on the northern range due to cooperative foraging behavior, their ability to take advantage of vulnerable ungulates, and their high population levels. Wolf extirpation has probably resulted in high coyote population densities and coyotes have, at least, partially slid into this vacant niche.

\section{$\checkmark \quad$ Literature Cited}

Altman, J. 1974. Observational study of behavior: sampling methods. Behavior 49:227-264.

Balser, D.S. 1965. Tranquilizer tabs for capturing wild carnivores. J. Wildl. Manage. 45:641649.

Crabtree, R.L. 1989. Social, spatial, and demographic characteristics of an unexploited coyote population. Ph.D. Thesis, University of Idaho, Moscow, ID. 79 pp.

F.G. Burton, T.R. Garland, D.A. Cataldo, and W.H. Rickard. 1989. Slow-release implants as individual markers for carnivores. J. Wildl. Manage. 53(4):949-954.

Dennis, B.D., R.L. Crabtree, and E.O. Garton. 1991. Statistical methods for closed population estimation using radioisotope tagging. J. Wildl. Manage.:(Submitted)

Dixon, K.R., and J.A. Chapman. 1980. Harmonic mean measure of animal activity. Ecology 61:1040-1044. 
Kelly, B. T. 1991. Carnivore scat analysis: and evaluation of existing techniques and the development of predictive models of prey consumed. M.S. Thesis, University of Idaho, Moscow, Idaho. $200 \mathrm{pp}$.

Knight, R.J., B.M. Blanchard, and D.J. Mattson. 1988. Yellowstone grizzly bear investigations: report of the Interagency Study Team 1987. U.S.D.I. National Park Service. 80 pp.

Leban, F. A., and R. L. Crabtree. 1988. Users manual for program OVERLAP. University of Idaho. 3 pp.

Mohr, C.O. 1947. Table of equivalent populations of North American small mammals. Am. Mild. Nat. 37:223-249.

Murie, O.J. 1940. Ecology of the coyote in Yellowstone. Nat. Park. Serv. Fauna Ser. No. 4. $206 \mathrm{pp}$.
Pollock, K.H., S.R. Winterstein, and M.J. Conroy. 1989. Estimation and analysis of survival distribution for radio-tagged animals. Biometrics 44:234-242.

Ter Braak, C.J.F., and I.C. Prentice. 1988. A theory of gradient analysis. Adv. Ecol. Res. 18:271-317.

White, G.C. 1984. Numerical estimation of survival rates from band recovery and biotelemetry data. J. Wildl. Manage. 47:716728.

Worton, B.J. 1989. Kernel methods for estimating the utilization distribution in home-range studies. Ecology 70:164-168. 